\title{
SPECTROPHOTOMETRIC ANALYSIS OF NECTAR PRODUCTION IN SILENE VULGARIS (CARYophyllaceae) $)^{1}$
}

\author{
Claudia L. Jolls, ${ }^{2}$ Thomas C. Chenier, and \\ CYNThia L. HATLEY ${ }^{3}$ \\ University of Michigan Biological Station, Pellston, Michigan 49769; and \\ Department of Biology, East Carolina University, Greenville, North Carolina 27858-4353; \\ Department of Biostatistics and Epidemiology, East Carolina University, \\ Greenville, North Carolina 27858-4353; and \\ University of Michigan Biological Station, Pellston, Michigan 49769
}

\begin{abstract}
Significant differences in nectar content were observed between hermaphrodite and female plants of the gynomonoeciousgynodioecious taxon, Silene vulgaris, from populations in northern lower Michigan. These differences in nectar sugar content were observable with a carbohydrate digestion technique involving sulfuric acid, phenol, and measurement of the color change with a spectrophotometer. A hand-held refractometer did not provide sufficient resolution to discern differences between the genders. Both genders were similar in the pattern of sugar content of nectar during floral development. A splitplot factorial design revealed significant differences both among individual plants and stages of floral phenology within each gender. The spectrophotometric technique and statistical analysis provided the needed resolution to discern differences between the genders that we relate to pollinator activity, levels of inbreeding depression, and the maintenance of gynodioecy in this taxon.
\end{abstract}

Nectar content and composition among taxa have received considerable attention in the past (Percival, 1961; Baker and Baker, 1976). Intraspecific variation in nectar production in time and space has been documented (Boetius, 1948; Percival, 1965) and related to environmental factors (Willmer, 1980; Bertsch, 1983; Hiebert and Calder, 1983) and flower age (Fahn, 1949; Pankratova, 1950; Pleasants, 1983). Recently, researchers have focused on variation in nectar production within as well as among taxa, relating nectar rewards to plant fitness (Best and Bierzychudek, 1982; Pleasants, 1983; Devlin, Horton, and Stephenson, 1986; Real and Rathcke, 1988). Although Fahn (1949) documented greater nectar rewards in female compared to male flowers of cucumber, the more recent interests in sexual selection, resource partitioning, and optimal foraging theory have spawned considerable work on differences in nectar between different sexual forms of the same species (Bawa and Opler, 1975; Perkins, Estes, and Thorp, 1975; Bawa, 1980; Cruden, Hermann, and Peterson, 1983; Bullock and Bawa, 1981; Pleasants, 1983; Devlin and Stephenson, 1985). Willson and Ågren (1989) reviewed differences in floral rewards 1993.

Received for publication 28 April 1992; revision accepted 3 July

The authors thank Robin M. Bush, Janelle Eads, Karen L. Hoffman, Martha N. Jones, Eileen Nordlie, and Sharon D. Smitherman for technical assistance; Don Holbert and Kevin O'Brien for statistical consultation; Suzanne Koptur, Bernadette Devlin, Stephen Bachmann, and two anonymous reviewers for thoughtful comments on the manuscript; and George, Ross, and Tyler Briggs for support and patience. This work was supported in part by the Naturalist-Ecologist Training Program of the University of Michigan Biological Station, funded by the Andrew W. Mellon Foundation, and revised while CLJ was the recipient of a NSF Research Opportunity Award at the Department of E.P.O. Biology, University of Colorado at Boulder, BSR-8840464, with Jane H. Bock and Alcinda Cundiff-Lewis.

${ }^{2}$ Author for correspondence.

${ }^{3}$ Current address: 4856 River Road, Cuylerville, NY 14481. between unisexual flowers; however, we know of very few intraspecific comparisons between unisexual and bisexual flowers. Seminal papers by Baker and Baker (1976), Bolten et al. (1979), and Inouye et al. (1980) have expanded our ability to study nectar composition, alerted us to sources of confusion and error, and stressed the need for standardized methods for reporting nectar sugar concentration and volume. We used a carbohydrate digestion technique documented elsewhere (Roberts, 1979) to report differences in time, between as well as within the sexes in nectar sugar content of the bladder campion, Silene vulgaris (Caryophyllaceae).

\section{MATERIALS AND METHODS}

Silene vulgaris (Moench) Garcke (also known as $S$. cucubalus Wibel) is a weedy, herbaceous perennial, widely distributed in temperate regions of Europe, Asia, North Africa, and North America. In North America, this taxon occurs from Newfoundland to British Columbia, south to Virginia and Tennessee, west to Kansas, Colorado, and Oregon (Rickett, 1966). Within a population, several different forms of individuals may exist: hermaphrodites with perfect flowers, females with rudimentary anthers, and less commonly, gynomonoecious forms with perfect flowers and unisexual flowers exhibiting varying degrees of male function.

We compared nectar production of hermaphrodite and female flowers using a spectrophotometric assay of carbohydrate digestion (Dubois et al., 1956; Roberts, 1979), used for minute quantities of dissolved sugar in flowers and insects. Sixty individuals of Silene vulgaris had been established since May 1983 in a common garden at the University of Michigan Biological Station, Cheboygan Co. $\left(45^{\circ} 33^{\prime} 30.370^{\prime \prime} \mathrm{N}, 84^{\circ} 40^{\prime} 27.516^{\prime \prime} \mathrm{W}, \mathrm{T} 37 \mathrm{~N}, \mathrm{R} 3 \mathrm{~W}\right.$, Sec. 33). These 60 plants had been selected without bias from individuals reared from seed and maintained since Sep- 


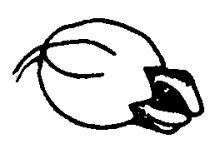

H 1

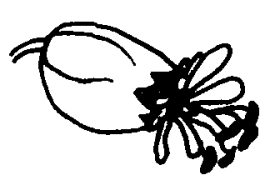

H 2

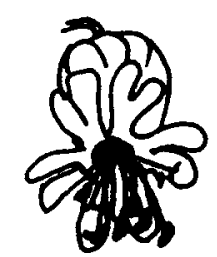

H 3

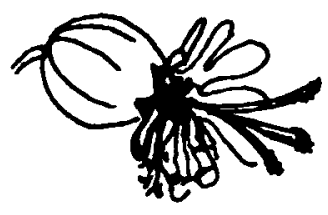

H 4

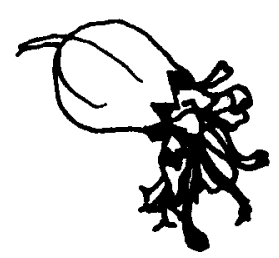

H 5

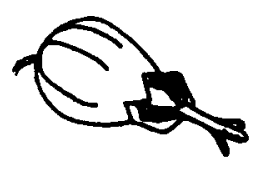

F1

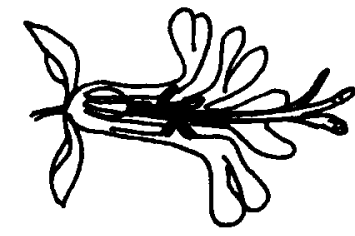

F 2

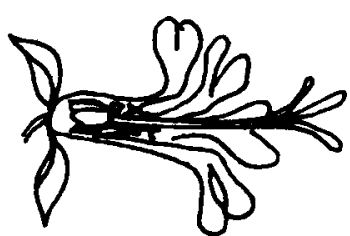

F 3

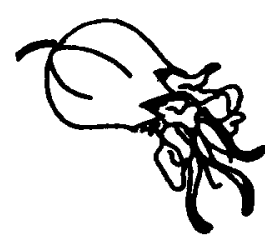

F 4

Fig. 1. Diagram of floral stages for hermaphroditic and female flowers. Those characters given greatest weight are presented in bold print. Top row, left to right, hermaphrodites: H1) bud opening, no anthers dehisced, style short (no flowers of this stage found); $H 2$ ) one to five anthers dehisced, style short; H3) five to ten anthers dehisced, style short; $\mathrm{H4}$ ) petals full, all anthers dehisced, filaments withering, style elongate and stigma papillae distinct; H5) petals withered, style elongate, filaments withered. Bottom row, left to right, females: F1) flowers opening, petals curled and pigmented, anthers may/may not be dehisced, stamens plump, style short and not fully elongate, papillae short; F2) flowers open, petals uncurling, pigmented or not, anthers dehiscing, stamens plump, style elongating and stigma papillae long and distinct; F3) flowers open, petals full and white, anthers dehisced, stamens and filaments, in particular, plump, style fully elongate, stigma papillae distinct; F4) petals full, stamens and particularly filaments, withered, style elongate, stigma papillae distinct; F5) petals withered, stamens withered, style beginning to curl and wither.

tember 1982 at Matthaei Botanic Garden greenhouses, University of Michigan, Ann Arbor, Michigan. On 23 June 1984, we selected five hermaphrodites from these 60 plants and four females based on number and phenology of flowers. Portions of the inflorescences (dichasia) were bagged with fine mesh curtain material to prevent nectar collection by insects. Approximately $24 \mathrm{hr}$ later, the flowers were harvested, placed in petri dishes lined with moistened filter paper, and stored in a refrigerator to prevent evaporation of nectar. We sorted flowers into one of five phenological stages, detailed in Fig. 1. The calyx of each flower was split, and the anthers were carefully removed with forceps. The flowers were placed into vials containing $3 \mathrm{ml}$ distilled water. The vials were shaken gently to wet the nectaries; the flowers were removed after 45-60 min. The rinsate was frozen until spectrophotometric analysis.

We diluted a $1-\mathrm{ml}$ sample of thawed flower rinsate; the number of dilutions necessary was determined by a test run. We then added $1 \mathrm{ml} 5 \%$ phenol, and $5 \mathrm{ml}$ concentrated sulfuric acid to the diluted floral rinsate. The solution was mixed and color allowed to develop for 45 min. Absorbance at $490 \mathrm{~nm}$ was measured using a Bausch and Lomb Spectronic 710 spectrophotometer. If the read- ing was off-scale, we diluted the sample again. We constructed a standard curve using serial dilutions of a 1:1:1 $0.3 \mathrm{~mm}$ solution of sucrose, fructose, and glucose. The amount of sugar $(\mathrm{mg})$ in each sample was calculated using the equation for the standard curve: $\mathrm{mg}$ sugar $/ \mathrm{ml}$ nectar $=0.0963 \times$ absorbance $+0.00017, r^{2}=0.998$.

Sugar content was compared between the sexes, among plants of a given sex and among the five floral stages using a split-plot factorial analysis of variance (also known as a randomized block design with replication, Kirk, 1982), a special type of incomplete block design. In this case, the two plant sexes (hermaphrodite or female) were assigned to the whole plot; each plot was subdivided by randomly assigning plants with a sex as subplots. This multifactor design is appropriate for repeated measures (phenological stage) for each subject (plant) when subjects are nested within treatments (sex) (Steel and Torrie, 1960; Sokal and Rohlf, 1969; Montgomery, 1984). The split plot design is a type of nested design but differs in that subjects (plants) within each group or treatment (sex) are measured at each point in time (stage). This design gives more information on differences between the sexes and among the plants within a given sex (Sokal and Rohlf, 1969). Data were transformed using natural logarithms 
TABLE 1. ANOVA table comparing sugar content of nectar per flower between the sexes, among plants and among floral stages. The splitplot tested Sex against the Plant (Sex) error term. Stage as well as Sex *Stage, the two repeated factors, were tested against a global error term, Plant-Stage (Sex). Analysis was performed on transformed data.

\begin{tabular}{lrcrr}
\hline \hline \multicolumn{1}{c}{ Source } & df & Sums of squares & $F$-value & \multicolumn{1}{c}{$P$} \\
\hline Sex & 1 & 20.5235 & 11.66 & 0.0112 \\
Plant (Sex) & 7 & 12.3246 & 7.14 & $\leq 0.0001$ \\
Stage & 3 & 45.4596 & 35.47 & $\leq 0.0001$ \\
Sex*Stage & 3 & 2.54046 & 1.98 & 0.1475 \\
Error & 21 & 8.9712 & & \\
\hline
\end{tabular}

to meet assumptions of normality for ANOVA. These same analyses were performed on ranked data for the nonparametric analogue of the ANOVA (Conover, 1980); in all cases, the inferences were the same. Analyses were performed using the GLM and other procedures in SAS (Statistical Analysis System, SAS Institute, Inc., Cary, NC) on an IBM 4381 mainframe computer at East Carolina University.

\section{RESULTS}

Significant differences in nectar sugar content were present between hermaphrodites and females $(P=0.0112)$, among plants within a sex $(P \leq 0.0001)$, and among stages of flower development ( $P \leq 0.0001$, Table 1). The differences between sexes, however, were consistent across stages, shown by the lack of significant sex by stage interaction. On average, hermaphrodites produced more sugar per flower than did females $(\bar{X} \pm \mathrm{SE}=0.933 \pm$ 0.059 vs. $0.548 \pm 0.052$, respectively).

Given the lack of significant stage by sex interaction, it is appropriate to look just at the differences among floral stages combining plants of both genders. Nectar sugar content increased then decreased through time in both sexes, peaking at floral stage three for hermaphrodites and stage four for females (Table 2). Stage one was excluded from the analysis because no hermaphrodite flowers in this stage of floral development were collected. Female flowers in stage one, however, averaged $0.1103 \pm 0.0272$ mg sugar $(N=10)$. Stages three and four were not statistically distinguishable using the Tukey-Kramer method as a posteriori simultaneous test procedures among stages (SAS Institute, Inc., 1985). Nectar rewards in terms of sugar content were greatest in flowers of both sexes during stigma receptivity, based on our observations of maximum development of the stigmatic papillae.

The significant interaction term of stages with plants within a given sex suggests variation among plants in the temporal pattern of sugar production. This difference among plants also is reflected in a significant plant nested within sex term (plant [sex], Table 1). First, plants differed as to whether sugar content was greatest at stage three or four (Table 2). Second, female flowers appeared more variable than hermaphrodites in their nectar sugar content (CV and $[N]=9.5 \%$ [70] vs. 6.3\% [97], respectively); however, differences in sample size may bias this comparison. Even within each sex at a given stage of development, with similar sample sizes, the coefficients of variation for female flowers exceeds those of hermaphrodites by at least $10 \%$ (Table 2 ).

\section{DISCUSSION}

Differences between the sexes of Silene vulgaris in nectar sugar content were observable using the simple digestion technique reported by Roberts (1979). An earlier pilot study using a hand refractometer had failed to discern differences between the sexes, probably due to small sample sizes and limited resolution of refractometers. The greater precision of digestion techniques can make them superior to refractometers for assessing variation within some taxa. McKenna and Thomson (1988) reported a similar technique for sampling small amounts of nectar using filter paper wicks and the anthrone reagent method of Umbreit, Burris, and Stauffer (1972). In both techniques, acid acts to hydrolyze sugars and the reagent reacts

TABLE 2. Means and standard errors for total sugar content of nectar per flower in $\mathrm{mg}$ for each plant of both genders at each floral stage.

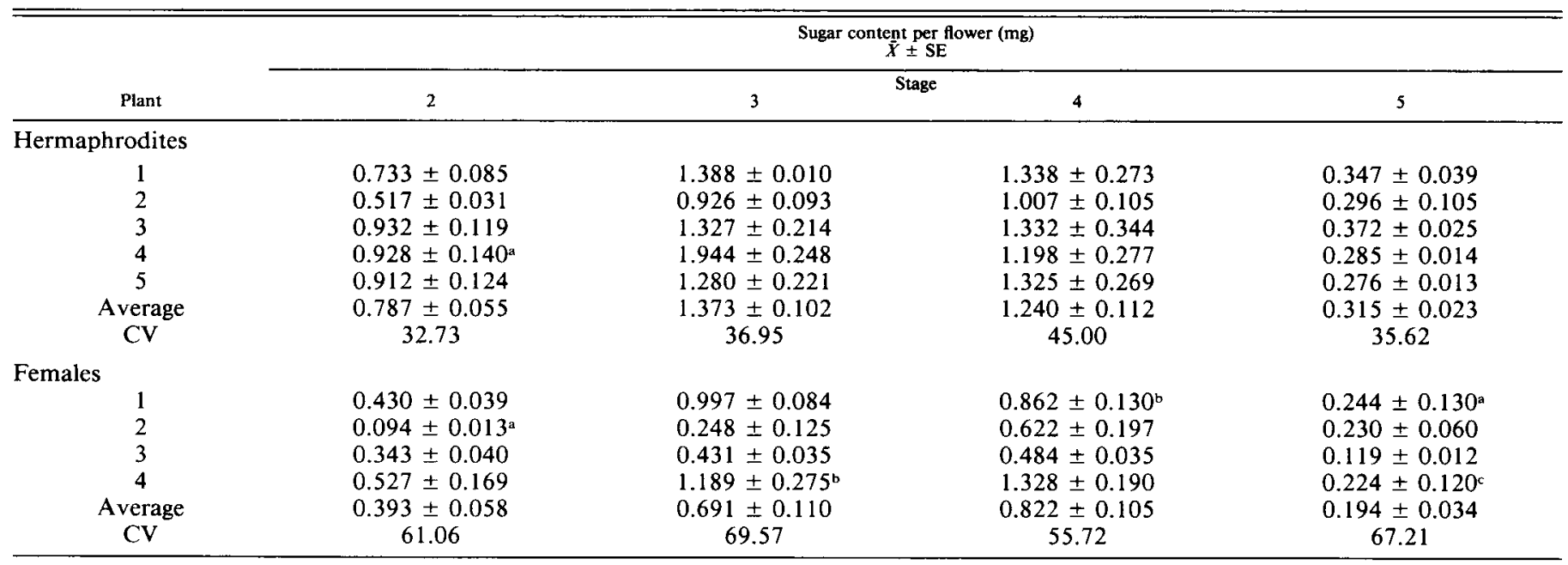

a $N=2$.

${ }^{\mathrm{b}} N=4$; all other means are based on sample sizes of five.

c $N=3$. 
with sugars' aldehyde groups to affect the color change. Roberts' (1979) technique is readily adaptable for wicking nectar with filter paper and then making a rinsate. We caution that both techniques are extremely sensitive to any source of carbohydrate. Flowers must be emasculated before rinsing, and shaking must dissolve nectar without tearing any tissues. Pollen, other floral tissues, and even lint from the filter paper could be digested from the reagent and contribute to absorbance (Roberts, 1979). Either technique can be adapted to nectars of different sugar compositions by adjusting the sugar standard; however, McKenna and Thomson (1988) found that the anthrone analysis was relatively insensitive to the proportions of sugars in the mixture.

Hermaphrodites of Silene vulgaris produced flowers with more available sugar than did females. The literature that discusses nectar differences between plant sexes is limited. The diversity of techniques used and the array of environmental conditions under which the varied data were collected make comparisons difficult. In the Caryophyllaceae, female-phase plants of the andromonoecious-gynomonoecious Viscaria vulgaris produced greater nectar volumes than male-phase individuals, but no differences in nectar sugar concentration were observed (Jennersten, Berg, and Lehman, 1988). In the dioecious relative, Silene dioica, males varied more in sugar per flower, although females produced a greater volume of more dilute nectar (Kay et al., 1984). The causes and consequences of such differences merit further inquiry. The differences we observed between morphs of Silene vulgaris appear to be genetic rather than environmental, given these were greenhouse-reared plants of the same age transplanted to a common garden. The significance of greater nectar production by hermaphrodites is counter-intuitive if we expect females to be pollen-limited and have evolved higher sugar content to encourage pollinator visits. Nuclear- and cytoplasmic-inheritance models for the maintenance of gynodioecy (Lewis, 1941; Lloyd, 1975; Ross, 1978) would predict that females should have greater reproductive output relative to hermaphrodites to compensate for their loss of pollen function. Hermaphrodites are larger, produce more flowers and seeds per plant, and now reported here, more sugar per flower relative to females, as well as a pollen reward (Jolls, 1984, and unpublished data). Greater nectar rewards and the presence of pollen within hermaphrodites may encourage within-plant fidelity by insects and its resultant self-fertilization, thus promoting inbreeding depression. Our preliminary data show no preference of one sex by visiting insects; however, the maintenance of females probably is related to the greater success of their progeny and inbreeding depression from selfing of hermaphrodites (Charlesworth, 1981; Jolls and Chenier, 1989; Pettersson, 1992).

By using the split-plot design, we observed significant variation in nectar sugar content among plants within a sex as well as between the sexes. Such differences among plants could be due to plant age, size, microsite, or even genetic differences. Sugar concentration and sugar content per flower do differ within and among plants due to environmental (Bertsch, 1983; Southwick and Southwick, 1983) and probably genetic effects (Devlin, Horton, and Stephenson, 1986). Our coefficients of variation suggest considerable variation within a sex; however, we did not statistically discern differences between sexes in variability of sugar content (in the sense of Real and Rathcke, 1988). We are cautious about our interpretation of these data. These data represent a subsample from plants of each sex; we do not present nectar sugar contents for all flowers present on each plant at one time. Also, flowers were bagged and do not reflect the true variability available to visiting pollinators. Within a plant, however, at any given time, flowers are present in different stages of development on any given individual; the inflorescence of Silene vulgaris is a dichasium. This inflorescence morphology makes for considerable within-plant variability in nectar and pollen rewards, as well as variation among individuals of the same sex. In addition to promoting selfing of bisexuals, variation within plants, between sexes, and the greater rewards of hermaphrodite flowers could encourage intersexual visitation by pollinators, promoting the necessary transfer of pollen from hermaphrodites to male-sterile individuals (Best and Bierzychudek, 1982). As is the case with many gynodioecious taxa, Silene vulgaris is strongly protandrous, preventing autogamy, and exclusively insect-pollinated. Estimates of selfing rates from allozyme data are relatively low (D. Charlesworth, University of Chicago, personal communication). As a result, selfing and the resultant inbreeding depression, which we and others hypothesize drives the evolution of gynodioecy, are insect-mediated in this taxon, making pollinator movements and gene flow critical to our understanding of this breeding system.

We agree with McKenna and Thomson (1988) that these carbohydrate digestion methods provide a more accurate determination of one aspect of floral rewards. Greater resolution may enable us to address to what extent variability in floral rewards can shape plant-pollinator interactions and coevolution (Real and Rathcke, 1988), and the role of pollinators in the maintenance and evolution of mixed breeding systems within a plant species.

\section{LITERATURE CITED}

BAKER, I., AND H. G. BAKER. 1976. Analyses of amino acids in flower nectar of hybrids and their parents, with phylogenetic implications. New Phytologist 76: 87-98.

BAwA, K. S. 1980. Mimicry of male by female flowers and intrasexual competition for pollinators in Jacaratia dolichuala (D. Smith) Woodson (Caricaceae). Evolution 34: 467-474.

- AND P. A. OPLeR. 1975. Dioecism in tropical forest trees. Evolution 29: 167-179.

BerTSCH, A. 1983. Nectar production of Epilobium angustifolium L. at different air humidities, nectar sugar in individual flowers and the optimal foraging theory. Oecologia 59: 40-48.

Best, L. S., AND P. Bierzychudek. 1982. Pollinator foraging on foxglove (Digitalis purpurea): a test of a new model. Evolution 36: 70 79.

Boetius, J. 1948. Über den Verlauf Der Nektarabsonderung einiger Blutenpflanzen, Beih Sweiz Bienenzeitung 2: 257-317.

Bolten, A. B., P. Feinsinger, H. G. Baker, and I. Baker. 1979. On the calculation of sugar concentration in flower nectar. Oecologia 41: 301-304.

Bullock, S. H., AND K. S. BAwa. 1981. Sexual dimorphism and the annual flowering pattern in Jacaratia dolichaula (D. Smith) Woodson (Caricaceae) in a Costa Rica rain forest. Ecology 62: 14941504.

Charlesworth, D. 1981. A further study of the problem of the maintenance of females in gynodioecious species. Heredity 46: 27-39.

Conover, W. J. 1980. Practical nonparametric statistics, 2d ed. John Wiley and Sons, New York, NY. 493 pp. 
Cruden, R. W., S. M. Hermann, and S. Peterson. 1983. Patterns of nectar production and plant-pollinator coevolution. In B. Bentley and T. Elias [eds.], The biology of nectaries, 80-125. Columbia University Press, New York, NY. 259 pp.

Devlin, B., J. B. Horton, AND A. G. Stephenson. 1986. Patterns of nectar production of Lobelia cardinalis. American Journal of Botany 117: 289-295.

, AND A. G. StePHenSON. 1985. Sex differential floral duration, nectar secretion and pollinator foraging in a protandrous species. American Journal of Botany 72: 303-310.

Dubois, M., K. A. Giles, J. K. Hamilton, P. A. Rebers, And F. Smith. 1956. Colorimetric methods for determination of sugars and related substances. Analytical Chemistry 28: 350-356.

FAHN, A. 1949. Studies in the ecology of nectar secretion. Palestine Journal of Botany, Jerusalem Series 4: 207-224.

Hiebert, S. M., AND W. A. CAlder, III. 1983. Sodium, potassium and chloride in floral nectars: energy-free contributions to refractive index and salt balance. Ecology 64: 399-402.

inouye, D. W., N. A. Favre, J. A. Lanum, D. M. LeVine, J. B. Meyers, M. S. Roberts, F. C. TSAO, AND Y.-Y. WANG. 1980. The effects of nonsugar nectar constituents on estimates of nectar energy content. Ecology 61: 992 -996.

Jennersten, O., L. Berg, and C. Lehman. 1988. Phenological differences in pollinator visitation, pollen deposition and seed set in the sticky catchfly, Viscaria vulgaris. Journal of Ecology 76: $1111-$ 1132.

Jolls, C. L. 1984. The maintenance of hermaphrodites and females in populations of Silene vulgaris (Moench) Garcke (Caryophyllaceae). American Journal of Botany 71: 80 (Abstract).

- - AND T. C. CHENIER. 1989. Gynodioecy in Silene vulgaris (Caryophyllaceae): progeny success, experimental design, and maternal effects. American Journal of Botany 76: 1360-1367.

Kay, Q. O. N., A. J. LaCk, F. C. Bamber, and C. R. Davies. 1984. Differences between sexes in floral morphology, nectar production and insect visits in a dioecious species, Silene dioica. New Phytologist 93: 515-529.

KIRK, R. E. 1982. Experimental design, 2d ed. Brooks/Cole, Monterey, CA.

LEWIS, D. 1941. Male sterility in natural populations of hermaphroditic plants. New Phytologist 40: 56-63.

LLOYD, D. G. 1975. The maintenance of gynodioecy and androgynodioecy in angiosperms. Genetica 45: 325-339.

McKenna, M. A., AND J. D. Thomson. 1988. A technique for sampling and measuring small amounts of floral nectar. Ecology 69: 13061307.

MONTGOMERY, D. C. 1984. Design and analysis of experiments, $2 \mathrm{~d}$. ed. John Wiley and Sons, New York, NY.

Pankratova, N. M. 1950. Investigation of the process of secretion of nectar. Zhurnal Obshchei Biologii 11: 292-305 (in Russian).

Percival, M.S. 1961. Types of nectar in angiosperms. New Phytologist 60: $235-281$.

—. 1965. Floral biology. Pergamon Press, Oxford.

Perkins, G. P., J. R. Estes, AND R. W. ThORP. 1975. Pollination of Cnidoscolus texanus (Euphorbiaceae) in south-central Oklahoma. Southwestern Naturalist 20: 391-396.

PetTersson, M. W. 1992. Advantages of being a specialist female in the gynodioecious Silene vulgaris s.l. (Caryophyllaceae). American Journal of Botany 79: 1389-1395.

Pleasants, J. 1983. Nectar production patterns in Ipomopsis aggregata (Polemoniaceae). American Journal of Botany 70: 1468-1475.

REAL, L. S., AND B. J. RATHCKE. 1988. Patterns of individual variability in floral resources. Ecology 69: 728-735.

Ricketr, H. W. 1966. Wild flowers of the United States. New York Botanic Garden, McGraw-Hill, New York, NY.

ROBERTS, R. B. 1979. Spectrophotometric analyses of sugars produced by plants and harvested by insects. Journal of Apicultural Research 18: 191-195.

Ross, M. D. 1978. The evolution of gynodioecy and subdioecy. Evolution 32: 174-188.

SAS InSTITUTE, INC. 1985. SAS user's guide: statistics, version 5 ed. SAS Institute, Inc., Cary, NC.

SoKAL, R. R., AND F. J. Rohlf. 1969. Biometry: the principles and practice of statistics in biological research. W. H. Freeman, San Francisco, CA. 776 pp.

Southwick, A. K., AND E. E. Southwick. 1983. Aging effect on nectar production in Asclepias syriaca. Oecologia (Berlin) 56: 121-125.

Steel, R. G. D., AND J. H. Torrie. 1960. Principles and procedures of statistics with special reference to biological sciences. McGrawHill, New York, NY.

Umbreit, W. W., R. H. Burris, AND J. H. Stauffer. 1972. Manometric and biochemical techniques. Burgess, Minneapolis, MN.

WiLlmer, P. G. 1980. The effects of insect visitors on nectar constituents in temperate plants. Oecologia 47: 270-277.

Willson, M. F., AND J. ÅgReN. 1989. Differential floral rewards and pollination by deceit in unisexual flowers. Oikos 55: 23-29. 